\title{
The effect of neo-rectal wall properties on functional outcome after colonic $\mathbf{J}$-pouch-anal anastomosis
}

\author{
Martijn P. Gosselink • David D. Zimmerman • \\ Rachel L. West • Wim C. Hop • Ernst J. Kuipers • \\ W. Rudolph Schouten
}

Accepted: 2 May 2007 / Published online: 23 May 2007

(C) Springer-Verlag 2007

\begin{abstract}
Background/aims It has been suggested that normal function of both anal sphincters is essential for a good functional outcome after colonic J-pouch-anal anastomosis (CPAA). However, CPAA patients may have impaired continence despite adequate sphincter function. The present study was designed to identify those factors, which contribute to the functional outcome after a handsewn CPAA.

Materials and methods Forty patients were studied before and 1 year after pouch surgery. Faecal continence was evaluated using the Rockwood faecal incontinence severity index (RFISI). At both occasions, maximum anal resting pressure (MARP) and maximum anal squeeze pressure (MASP) were recorded. In addition, sensory perception threshold-volumes (SPT-V) and compliance were assessed using an 'infinitely' compliant polyethylene bag connected to an electronic barostat assembly.
\end{abstract}

M. P. Gosselink • D. D. Zimmerman • W. R. Schouten

Colorectal Research Group of the Department of Surgery,

Erasmus MC,

Rotterdam, The Netherlands

R. L. West • E. J. Kuipers

Department of Gastroenterology and Hepatology, Erasmus MC,

Rotterdam, The Netherlands

W. C. Hop

Department of Epidemiology and Biostatistics, Erasmus MC,

Rotterdam, The Netherlands

W. R. Schouten $(\triangle)$

Department of Surgery, H1043,

Erasmus Medical Center Rotterdam (Dijkzigt),

Dr. Molewaterplein 40,

3015 GD Rotterdam, The Netherlands

e-mail: w.r.schouten@erasmusmc.nl
Results The median RFISI score 1 year after surgery was higher than the median RFISI score before surgery (13 vs 7 $(p<0.01)$. The median MARP dropped significantly $(p<$ $0.01)$ whereas the median MASP remained unaffected. The mean compliance, calculated at three different sensation levels, and the pouch sensory perception threshold-volumes (PSPT-V) were lower than those of the original rectum $(p<$ 0.05 ). The reduction of MARP showed no correlation with the post-operative change in RFISI scores. Low PC and low PSPT-V were associated with higher RFISI scores.

Conclusion Low pouch compliance and low SPT-V adversely affect functional outcome after a handsewn colonic J-pouch-anal anastomosis.

Keywords Colonic J-pouch-anal anastomosis . Functional outcome $\cdot$ Neo-rectal wall properties .

Total meso-rectal excision $\cdot$ Rectal cancer

\section{Introduction}

After total meso-rectal excision for rectal cancer, surgeons often try to avoid an abdomino-perineal resection by performing a trans-anally double-stapled low colorectal anastomosis (LRA), often without a pouch. The functional outcome after such a LRA is not as good as previously thought $[1,2]$, especially after pre-operative radiotherapy $[3$, 4]. It has been shown that the addition of a pouch improves the functional outcome and quality of life $[5,6]$. A poor functional outcome after LRA or straight colo-anal anastomosis without a pouch is characterised by a high defaecation frequency, urgency and impaired continence, especially during the first 2 years after the operation. Decrease in internal and external anal sphincter functions due to direct injury of the nervous supply [7, 8], abolishment of the recto- 
anal inhibitory reflex $[9,10]$ and the level of the anastomosis [11] have been related to functional impairment after LRA. In a recent study, we demonstrated that poor functional outcome after handsewn colonic J-pouch-anal anastomosis (CPAA) utilising a Scott retractor was not due to alterations of the anal sphincters [12]. The question therefore is whether other factors such as pouch compliance and pouch sensory perception attribute to functional outcome. A recent metaanalysis conducted by Heriot et al. revealed that pouch sensory perception threshold-volumes (PSPT-V) are larger in patients with a CPAA than in those with a straight anastomosis. However, no difference was found for resting or squeeze pressure [5].

Although functional outcome after CPAA is better than after low colorectal anastomosis without a pouch, a number of patients with a CPAA have impaired continence despite adequate sphincter function. The aim of our study was to investigate whether compliance and sensory perception are different in a colonic J-pouch compared to the original rectum. In addition, a possible relationship between compliance and sensory perception and functional outcome was evaluated.

\section{Materials and methods}

Between January 1999 and June 2003, 46 consecutive patients entered the study after signing informed consent. Forty patients presented with cancer located in the middle or lower third of the rectum. Six patients had a large villous adenoma of the rectum, which was un-suitable for endoscopic resection. Before the operation, all 46 patients underwent anal manometry and barostat measurements. One year after surgery, these measurements were repeated in 40 patients. In addition, patients were asked to fill out a questionnaire to assess faecal continence at both occasions. In six patients, this post-operative evaluation could not be performed. Two patients had died within 1 year after the operation. The cause of their death was not related to the procedure or their underlying cancer. In the other four patients, the surgeon had decided to perform an abdominoperineal resection during surgery. Nine patients who were evaluated 1 year after the operation received pre-operative radiotherapy. The radiotherapy was applied through a posterior-anterior field and 2 lateral fields with a total dosage of 25 Gy $(5 \times 5 \mathrm{~Gy})$. The target volume of the radiotherapy consists of the primary tumour and the mesentery with the vascular supply containing the perirectal, pre-sacral and internal iliac nodes. Eight patients with stage III rectal cancer and 1 patient with stage II rectal cancer received adjuvant chemotherapy; 6 months of 5fluorouracil given along with leucouvorin. None of the patients had any detectable signs of local recurrence or distant metastases at 1-year follow-up. There was no history of neurological disease, connective tissue disorder or diabetes mellitus in any of the patients. The study was approved by the ethical committee of the Erasmus MC.

\section{Surgery}

All patients were operated on by one colorectal surgeon (W.R.S). A total meso-rectal excision was performed with central ligation of the inferior mesenteric artery and vein including autonomic nerve preservation. The left part of the colon was mobilised proximally to the splenic flexure. The rectum was mobilised until the pelvic floor was reached. Just above the pelvic floor, the rectum was transected between two right-angled bowel clamps. To gain access to the anal canal, a Scott retractor was used (Lone Star Retractor System, Lone Star Medical Products, Houston, TX, USA). The remaining mucosa was removed from the dentate line up to the upper margin of the transected mucosa. For the construction of the 5to 7-cm-long colonic J-pouch, the distal part of the descending colon was used. All epiploic appendices were removed to reduce the amount of fatty mass. The colonic J-pouch was anastomosed to the dentate line with interrupted sutures Maxon 3.0 (United States Surgical Corporation, Norwalk, CT, USA). None of the patients had a temporary diverting ileostomy or trans-anal drains. All patients were immobilised for 5 days. During this period, metronidazole and cefuroxime were administered intravenously three times daily.

\section{Anal manometry}

Between 1999 and October 2001, a micro-tip pressure transducer (Millar Instruments, Houston, TX, USA) with an outside diameter of $1.7 \mathrm{~mm}$ and after October 2001, a dynamic pull-through technique $(2 \mathrm{~mm} / \mathrm{s})$ with a 4-channel water-perfused $(0.5 \mathrm{ml} / \mathrm{min})$ catheter (MMS system, Enschede, The Netherlands) were used for manometry. No specific bowel preparation was used. To perform manometry, patients were positioned in the left lateral position. Zero pressure calibration was done at the anal orifice level before introducing the catheter. After introduction and stabilisation in the rectum, the catheter was withdrawn. The high-pressure zone was registered; this was defined as an increase in pressure of more than $5 \mathrm{mmHg}$. Maximum anal resting pressure (MARP) was averaged across the four channels by using the maximum plateau phase of all channels. After introducing the catheter a second time, the patient was asked to squeeze at $0.5-\mathrm{cm}$ intervals. The maximum squeeze pressure was calculated by averaging the highest squeeze pressures recorded by each channel. The recto-anal inhibitory reflex was elicited by distending a rectal balloon with different volumes of air. Paradoxical straining was defined as an increase of $10 \mathrm{mmHg}$ combined with a maximum resting pressure of more than $60 \mathrm{mmHg}$. 


\section{Barostat measurement}

For this study, both ends of a thin, 'infinitely' compliant polyethylene bag were fastened hermetically to 1 side of a polyvinyl catheter $(7 \mathrm{~mm}$ in the outer diameter and marked at each $10 \mathrm{~cm}$ ) proximal and distal of 5 holes, covering a distance of 5 to $7 \mathrm{~cm}$ from the end of the catheter [13]. Before surgery, this bag was attached at a distance of 5 to $7 \mathrm{~cm}$ from the end of the catheter. After pouch construction, the bag was fastened at $4-5 \mathrm{~cm}$. The bag is fastened at both ends of the polyvinyl catheter to prevent axial expanding thereby allowing the bag to fully engage the circumference of the rectal wall. No tension is created in the walls of the bag in the interval between $0-600 \mathrm{cc}$ of air and therefore, distension pressure is transferred entirely on the rectal wall.

The catheter was linked to a strain gauge and a computercontrolled air injection system (G\&J Electronics, Ontario, Canada). The device was switched on at least $45 \mathrm{~min}$ before the measurement to allow the device to warm up. This time allows for the temperature drift of the pressure transducer to reach its maximum.

All patients and control subjects were asked to attempt to empty their bladder and rectum before measurement.

With the patient in left lateral position, the bag was inserted into the rectum, $10 \mathrm{~cm}$ from the anal canal. This was accomplished with the help of the scale on the catheter. Before each measurement, approximately $50 \mathrm{cc}$ of air was injected into and aspirated from the bag to un-fold it. After this, the bag was inflated with air to selected pressureplateaus (range $0-60 \mathrm{mmHg}$; rising in cumulative steps of $2 \mathrm{mmHg}$ at a stimulation duration of $10 \mathrm{~s}$ ) with the help of the computer-controlled electromechanical barostat system. Volume changes at the various levels of distending pressures were recorded and expressed in cc of air.

Subjects were instructed to report when they experienced the first sensation of content in the rectum (FS), earliest urge to defaecate (EUD) and maximum tolerable volume (MTV). The various levels of distending pressures needed to evoke these different sensations were noted. First, the entire pressure--volume curves of all patients, before and after surgery, and control subjects were plotted and compared. Second, the compliance of the rectal wall was calculated by taking the slope of the pressure--volume curve $(\Delta V / \Delta p)$ at the three different sensation levels.

Faecal incontinence score

A questionnaire was used to determine the faecal incontinence severity index (FISI) score before and after surgery [14]. This is a validated index based on a type $\mathrm{X}$ frequency matrix. The matrix includes four types of leakage commonly found in the faecal incontinent population: gas, mucus, liquid and solid stools and five frequencies: once to three times per month, once per week, twice per week, once per day and twice per day. For the specification of the weighting scores, patient input was used. Scores range from 0 (total continence) to 61 (complete incontinence to solid stool on a daily basis).

\section{Statistical analysis}

Differences in the FISI score, ano-rectal manometry and barostat measurements before and after surgery were evaluated using the Wilcoxon signed ranks test (median, $p$ value). Nominal data before and after surgery were compared with McNemar's test. Spearman's correlation coefficients were used for the evaluation of the changes in ano-rectal manometry and barostat findings vs FISI score. Comparison of changes between patient groups was conducted using the Mann-Whitney test. The limit of statistical significance was set at $p=0.05$ (two-sided).

\section{Results}

Demographic characteristics and oncological data of all patients are listed in Table 1. Minor complications occurred in 4 out of $40(10 \%)$ patients. Two patients developed urinary retention. Another patient was treated for symptoms of urinary tract infection. A fourth patient suffered from abdominal wound infection. None of the patients experienced post-operative clinical anastomotic leakage.

One year after surgery, the median Rockwood faecal incontinence severity index (RFISI) score was found to be increased (pre-operative $=6$, post-operative $=13 ; p<0.01$ ) (Table 2). With respect to the increase of this score, no differences were found between patients with and without pre-operative radiotherapy (15 and 12 , respectively).

Comparing pre-operative and post-operative manometric measurements, the median MARP was found to be significantly lower $(p<0.02), 1$ year after the operation. The median maximum anal squeeze pressure (MASP) remained the

Table 1 Baseline characteristics

Demographic characteristics and oncological data of all patients

\begin{tabular}{ll}
\hline Number of patients & 40 \\
Median age (years) (range) & $57(41-74)$ \\
Median time interval after surgery (months) & $12(10-15)$ \\
Male/female & $26 / 14$ \\
Tumour stage & \\
Villous adenoma (\%) & $7(17)$ \\
Stage $\mathrm{I}=\mathrm{T}_{1-2} \mathrm{~N}_{0} \mathrm{M}_{0}(\%)$ & $9(23)$ \\
Stage $\mathrm{II}=\mathrm{T}_{3-4} \mathrm{~N}_{0} \mathrm{M}_{0}(\%)$ & $16(40)$ \\
Stage $\mathrm{III}=\mathrm{T}_{1-4} \mathrm{~N}_{1} \mathrm{M}_{0}(\%)$ & $8(20)$ \\
Pre-operative radiotherapy (\%) & $9(23)$ \\
Post-operative chemotherapy (\%) & $5(13)$ \\
\hline
\end{tabular}


Table 2 RFISI scores and anorectal manometric findings before and 1 year after pouch construction

\begin{tabular}{llll}
\hline & Pre-operative & Post-operative & $\begin{array}{c}\text { Statistical } \\
\text { significance }\end{array}$ \\
\hline $\begin{array}{c}\text { RFISI } \\
\text { score } \\
\begin{array}{c}\text { MARP } \\
(\mathrm{mmHg})\end{array}\end{array}$ & $65(0-30)$ & $13(0-44)$ & $p<0.001$ \\
$\begin{array}{c}\text { MASP } \\
(\mathrm{mmHg})\end{array}$ & $163(59-363)$ & $151(55-324)$ & $p=0.19$ \\
\begin{tabular}{l} 
RAIR \\
\hline
\end{tabular} & $100 \%$ & $58 \%$ & $p<0.01$ \\
\hline
\end{tabular}

Values are presented as the median (range).

RFISI score: Rockwood Faecal Incontinence Severity Index, MARP: maximum anal resting pressure, MASP: maximum anal squeeze pressure, RAIR: recto-anal inhibitory reflex.

same. The observed changes in MARP showed no correlation with the post-operative alterations in RFISI scores. The reduction of MARP was significantly greater in the patients who received pre-operative radiotherapy $(25 \%$ vs $43 \%, p=$ 0.02). The MASP was not affected by pre-operative

Table 3 RFISI scores, anorectal manometric findings and barostat measurements 1 year after pouch construction in patients with or without pre-operative radiotherapy

\begin{tabular}{llll}
\hline & $\begin{array}{l}\text { Without pre- } \\
\text { operative } \\
\text { radiotherapy }\end{array}$ & $\begin{array}{l}\text { Pre-operative } \\
\text { radiotherapy }\end{array}$ & $\begin{array}{l}\text { Statistical } \\
\text { significance }\end{array}$ \\
\hline $\begin{array}{l}\text { Number of } \\
\text { patients }\end{array}$ & 31 & 9 & \\
RFISI score & $12(0-40)$ & $15(0-30)$ & $p=0.29$ \\
$\begin{array}{l}\text { MARP } \\
\text { (mmHg) }\end{array}$ & $49(29-88)$ & $37(21-79)$ & $p<0.02$ \\
$\begin{array}{l}\text { MASP } \\
\text { (mmHg) }\end{array}$ & $156(55-324)$ & $135(67-280)$ & $p=0.20$ \\
$\begin{array}{l}\text { RAIR } \\
\text { Volume FS }\end{array}$ & $51 \%(17-100)$ & $42 \%(8-78)$ & $p=0.37$ \\
$\begin{array}{l}\text { Volume } \\
\text { EUD }\end{array}$ & $116(32-193)$ & $92(25-210)$ & $p=0.11$ \\
$\begin{array}{l}\text { Volume } \\
\text { MTV }\end{array}$ & $166(71-280)$ & $138(40-255)$ & $p=0.23$ \\
Compliance & $3.7(1.6)$ & $5.1(2.1)$ & $p=0.52$ \\
$\begin{array}{l}\text { FS } \\
\text { Compliance }\end{array}$ & $4.3(1.2)$ & $3.2(0.8)$ & $p=0.07$ \\
$\quad$ EUD & & $3.8(1.1)$ & $p=0.09$ \\
Compliance & $4.9(0.9)$ & & \\
MTV & & & \\
\hline
\end{tabular}

Values are presented as the median (range).

Median volume thresholds (and range) and compliance (mean value and standard deviation) for (neo)rectal filling sensations during isobaric phasic distention (median values and range).

RFISI score: Rockwood Faecal Incontinence Severity Index, MARP: maximum anal resting pressure, MASP: maximum anal squeeze pressure, RAIR: recto-anal inhibitory reflex, $F S$ : first sensation, EUD: earliest urge to defaecate, $M T V$ : maximum tolerated volume.

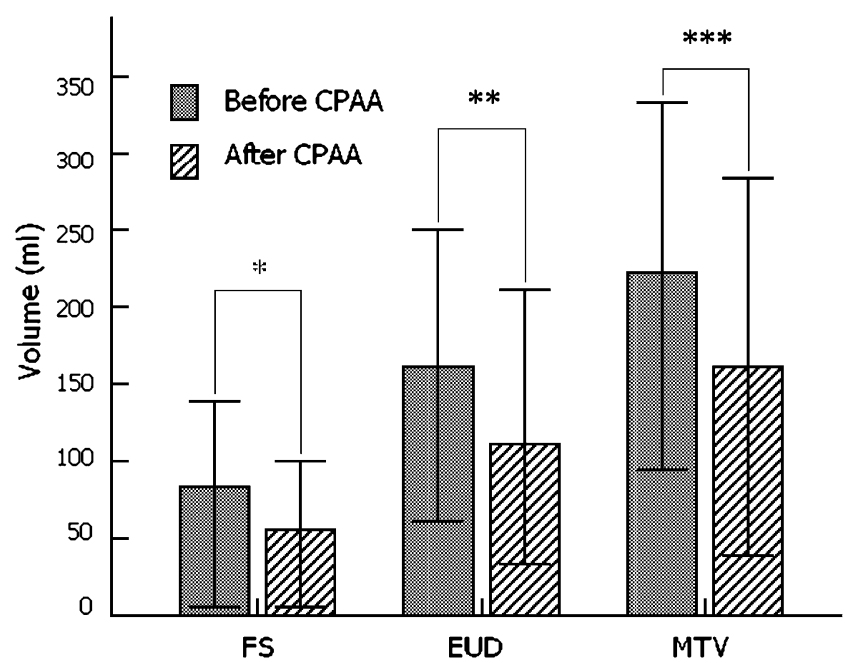

Fig. 1 Volume thresholds for (neo)rectal filling sensations during isobaric phasic distention (median values and range). FS first sensation, EUD earliest urge to defaecate, $M T V$ maximum tolerated volume, CPAA colonic J-pouch-anal anastomosis. ${ }^{*} p=0.008,{ }^{* *} p=$ 0.018 and ${ }^{* * *} p=0.009$ (Wilcoxon signed rank test)

radiotherapy. The results of the anal manometry and barostat measurements in patients with or without radiotherapy are shown in Table 3. Before operation, the recto-anal inhibitory reflex (RAIR) was present in all patients. One year after surgery, this reflex was detected in $58 \%$ of the patients $(p<$ $0.01)$. The presence or absence of this reflex did not influence the final RFISI score $(p=0.11)$.

During rectum distension with stepwise increasing pressures, the pressure-volume curves showed an S-shaped form in all patients. One year after the operation, the neorectal pressure-volume curves showed a similar S-shaped form. The PSPT-V for the FS, EUD and MTV were significantly lower than those obtained in the original rectum (all $p<0.02$ ) (Fig. 1). Comparing patients with and without pre-operative radiotherapy, no differences were found in the PSPT-V. At 1-year follow-up, the mean compliance calculated from $\Delta V / \Delta p$ at the different sensation levels was significantly lower than the compliance of the original rectum (Fig. 2). Pouch compliance was not affected by pre-operative radiotherapy (Table 3 ).

There was a significant correlation between the increase in RFISI score and the post-operative decrease in SPT-V for EUD and MTV ( $p=0.02$ and $p=0.002$, respectively). The increase in RFISI scores also correlated with the post-operative reduction in compliance calculated at each point of individual perception thresholds (FS, $p=0.01$; EUD, $p=0.005$; MTV, $p=$ 0.003) (Fig. 3).

\section{Discussion}

After total meso-rectal excision for rectal cancer, surgeons often try to avoid an abdomino-perineal resection by 
Before CPAA

口 After CPAA

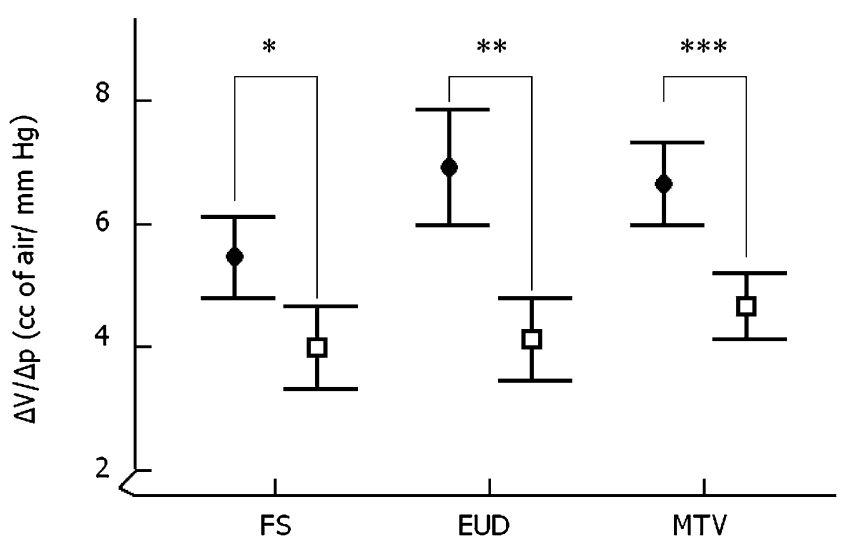

Fig. 2 Compliance, calculated at each point of sensory perception threshold, during isobaric phasic distention (mean values and standard deviation). $F S$ first sensation, $E U D$ earliest urge to defaecate, MTV maximum tolerated volume, CPAA colonic J-pouch-anal anastomosis. ${ }^{*} p=0.036,{ }^{* *} p=0.001$ and ${ }^{* * *} p=0.001$ (Wilcoxon signed rank test)

performing a trans-anal double-stapled low colorectal anastomosis, often without a pouch. The functional outcome after such an anastomosis is not as good as previously thought [1], especially after pre-operative radiotherapy $[3,4]$. In most patients, a poor functional outcome is characterised by a high defaecation frequency, urgency and impaired continence, especially during the first 2 years after the operation. The exact incidence of these defaecation disturbances is unknown. A recent study indicated that 1 year after a doublestapled side-to-end colorectal anastomosis without a pouch, $30 \%$ of the patients still experience problems with their bowel function, adversely affecting their daily life [15]. A straight colo-anal anastomosis without a pouch is associated with similar problems. Almost all patients encounter defaecation disturbances during the first 2 years after the procedure. In approximately one third of the patients, these problems become a permanent disability [16-18]. During the last two decades it has become clear that the addition of a pouch improves the functional outcome and quality of life after colo-anal anastomosis $[5,6]$. This statement is supported by the findings of our study. The median postoperative RFISI score observed in our patients was 13. It seems likely that this minor deterioration of continence did not affect the quality of life of our patients because it has been reported that only a score of over 30 has a detrimental effect on quality of life [19].

Fig. 3 Correlation analysis showing the inverse relationship between the change in RFISI scores and the changes in compliance calculated at each point of sensory perception. FS first sensation, EUD earliest urge to defaecate, MTV maximum tolerated volume, RFISI Rockwood Faecal Incontinence Severity Index

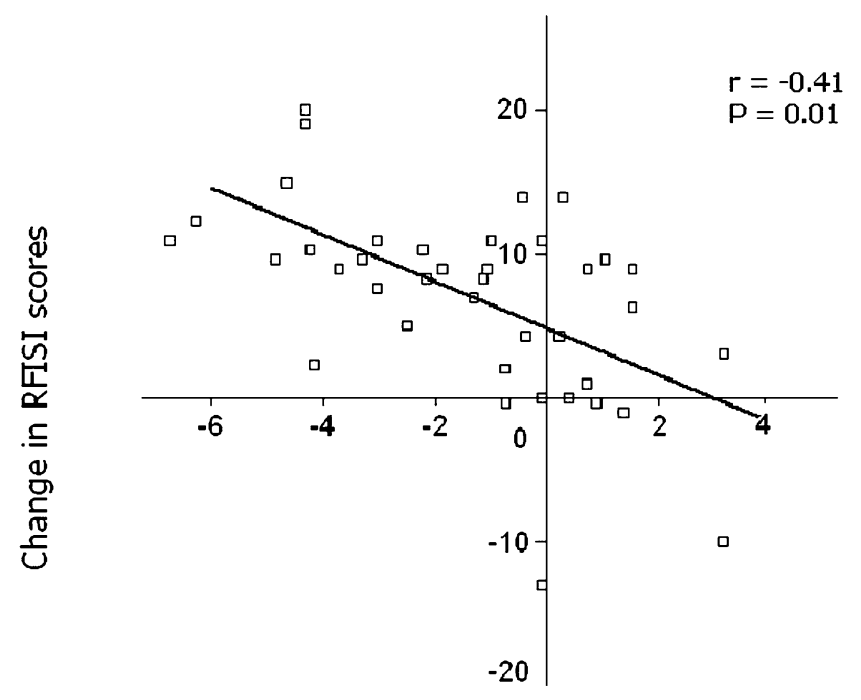

Change in Compliance at FS (cc of air/ $\mathrm{mm} \mathrm{Hg}$ )

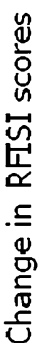

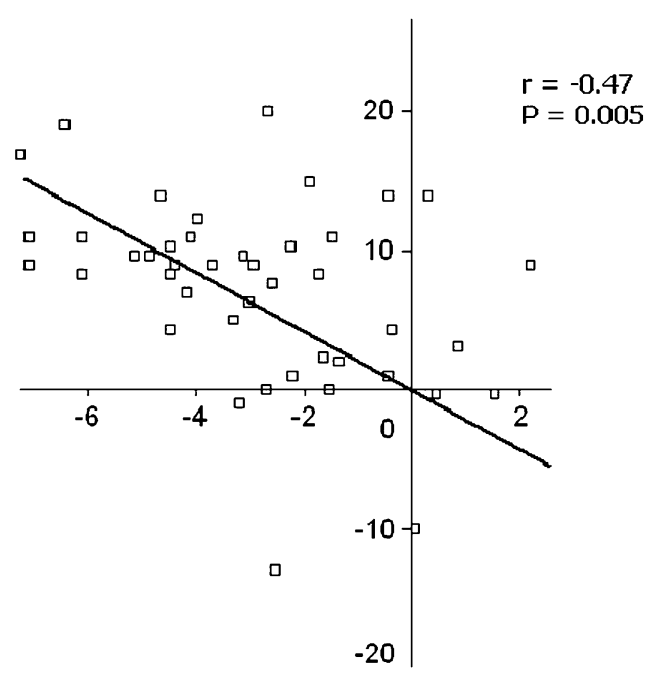

Change in Compliance at EUD (cc of air/ $\mathrm{mm} \mathrm{Hg}$ )

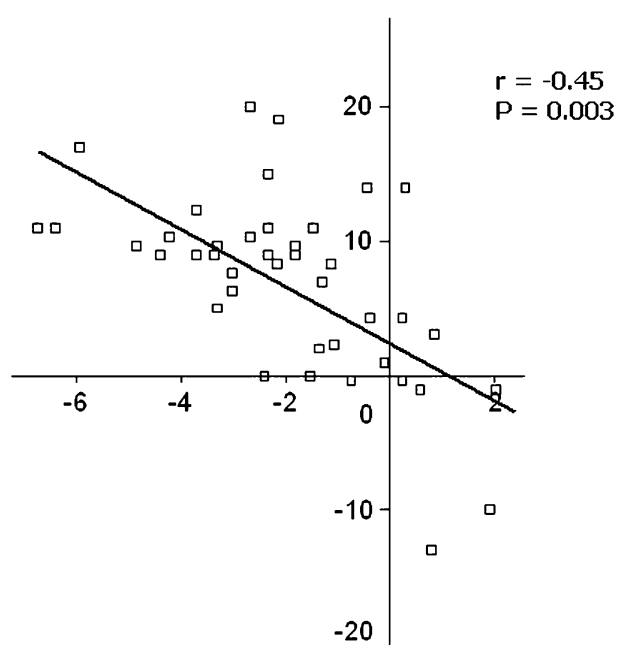

Change in Compliance at MTV (cc of air/ $\mathrm{mm} \mathrm{Hg}$ ) 
It has been shown that total meso-rectal excision results in a sustained reduction of maximum anal resting pressure, irrespective of the level and the type of the anastomosis [1, $6,20-23]$. Based on this finding, it seems unlikely that this pressure drop affects the functional outcome. In the present study, we observed an overall pressure drop of $30 \%$. However, this significant reduction of MARP showed no correlation with post-operative alteration in RFISI scores. The patients who received pre-operative radiotherapy encountered an even more pronounced pressure drop of $52 \%$. A similar finding has been reported by other authors $[24,25]$. According to these authors, irradiation is associated with internal anal sphincter damage, thereby resulting in impaired ano-rectal function. However, all their patients underwent a low colorectal anastomosis without a pouch. Two recent studies have revealed that the detrimental effect of pre-operative radiotherapy on functional outcome is less explicit in patients who underwent a colonic J-pouch-anal anastomosis [26, 27]. Our present study confirms these findings. We could not demonstrate any correlation between the reduction of MARP and the functional outcome in our patients who received pre-operative radiotherapy.

At 1-year follow-up, we did not find a significant reduction in MASP and thereby no correlation with the final RFISI score. In a previous study, we have shown that a pouch-anal anastomosis, hand-sutured to the dentate line with the help of a Scott retractor, does not affect the EAS. The volume, length and thickness of this muscle did not change and MASP remained un-affected [2]. Zimmerman et al. conducted a randomised trial to compare the Park's retractor vs the Scott retractor with regards to their impact on faecal continence after fistula repair [28]. MARP and RFISI scores deteriorated significantly after the use of a Park's retractor whereas these changes were not observed when the repair was performed with a Scott retractor. In ileoanal pouch surgery, it has been speculated that functional outcome could be improved by preserving the anal transition zone. The anal transition zone, thought to be important in continence, contains nerve endings that differentiate solid and liquid stools from gas. However, three prospective, randomised trials have demonstrated no significant difference in functional results for patients in whom a mucosectomy was performed vs those patients in whom the proximal anal canal mucosa was preserved [29-31].

Based on our manometric findings it is obvious that other factors contribute to the functional outcome after a colonic J-pouch-anal anastomosis. During the last decade, several studies have evaluated compliance and SPT-V in patients with and without a colonic pouch. With respect to the influence of compliance and sensory perception on functional outcome, the reported data are rather conflicting. Four studies suggest that the better outcome after a CPAA is due to a higher compliance with associated higher SPT-V
[22, 32-34]. In contrast, three other studies revealed that the neo-rectal wall properties had no detectable influence on functional outcome [35-37]. The authors of these three studies suggested that the better functional outcome in patients with a CPAA might be due to the design of the pouch with its anisoperistaltic limb resulting in the reversal of propulsive movements. In the present study, we investigated the influence of neo-rectal wall properties on the functional outcome among patients with a uniform pouch design. We did not compare patients with and without a pouch. Even in our patients with a uniform pouch design, we found a significant correlation between neo-rectal wall properties and functional outcome: the higher the compliance, the better the outcome. However, the configuration of the pouch may not be too large because long-term evacuation problems may occur. The optimal pouch size used for reconstruction was evaluated in 2 prospective randomised trials comparing a long $(10 \mathrm{~cm})$ vs a short $(5-6 \mathrm{~cm}) \mathrm{J}$-pouch $[38,39]$. In both studies, the short pouch was accompanied by a better evacuation function and a reduced use of laxatives or suppositories. In our study, the mean length of the J-pouch varied between 5 and $7 \mathrm{~cm}$. Three of our patients complained of evacuation difficulties after CPAA. These patients were successfully treated with retrograde colonic irrigation, as described in a previous study [40]. Data reported by van Duijvendijk et al. also illustrate the impact of compliance and sensory perception [41]. They examined the influence of preoperative radiotherapy on the functional outcome after trans-anally double-stapled low colorectal anastomosis by comparing patients with and without radiotherapy. They found that in the patients who received radiotherapy, compliance was significantly lower, which was associated with a higher defaecation frequency and faecal incontinence. In our study, we were not able to demonstrate this detrimental effect of pre-operative radiotherapy. All our colonic pouches were constructed of the non-irradiated distal part of the descending colon. These pouches were sutured to the dentate line after removing the entire irradiated rectum. Based on our findings, it seems preferable to create a colonic pouch-anal anastomosis rather than to leave an irradiated rectal remnant for a low colorectal anastomosis. Our $r$-squared values do suggest that compliance and sensory perception are not the only factors contributing to the functional outcome after a colonic Jpouch-anal anastomosis. Another study is warranted to investigate these other factors.

In the treatment of patients with cancer located in the middle or lower third of the rectum, total meso-rectal excision is now being established as the therapeutic gold standard. After this procedure, a trans-anally double-stapled anastomosis can only be constructed at the level of or just above the pelvic floor. Most surgeons believe that the 
preservation of a short rectal remnant is beneficial for the patient. However, it has been shown that this does not offer any functional advances [11, 42]. Moreover, most surgeons under-estimate the high risk of anastomotic leakage after the construction of such a low anastomosis. Recently, a population-based study from Sweden revealed that the incidence of this serious complication was $24 \%$ when the anastomosis was located within $6 \mathrm{~cm}$ from the anal verge [43]. Such an anastomotic leakage in this region is associated not only with a high morbidity, but also with a significant mortality [44]. It has also been reported that an anastomotic leakage adversely effects disease-free survival [45]. The reported incidence of anastomotic leakage after colonic Jpouch-anal anastomosis varies between $0 \%$ and $9 \%$, which seems to be much lower than after a double-stapled low rectal anastomosis [46, 47]. This is in agreement with our own experience. None of our patients received a temporary diverting ileostomy. Nevertheless, we did not observe any anastomotic breakdown after the procedure. Further studies that address this issue are needed.

During the last decade, it has been demonstrated that the transverse coloplasty pouch, as described by Z'Graggen et al. from Bern, is a good alternative for the colonic J-pouch [48]. There is growing evidence that both pouches have similar wall properties and comparable functional outcome [36, 49, 50]. Mantyh et al. compared neo-rectal wall properties and functional results among patients receiving a transverse coloplasty pouch, a colonic J-pouch or a straight anastomosis [49]. Compliance and sensory perception were found to be higher in patients with a pouch than in patients with a straight anastomosis. This was associated with a better functional outcome. Based on these findings and those obtained from the present study, it is obvious that both neorectal compliance and neo-rectal sensory perception are major contributing factors to a good functional outcome after total meso-rectal excision. In our opinion, all patients who are scheduled for total meso-rectal excision should be offered either a colonic J-pouch or a coloplasty pouch, especially to overcome the poor early post-operative function after straight colo-anal anastomosis.

\section{References}

1. Williamson ME, Lewis WG, Finan PJ, Miller AS, Holdsworth PJ, Johnston D (1995) Recovery of physiologic and clinical function after low anterior resection of the rectum for carcinoma: myth or reality? Dis Colon Rectum 38(4):411-418

2. Gosselink MP, Busschbach JJ, Dijkhuis CM, Stassen LP, Hop WC, Schouten WR (2006) Quality of life after total mesorectal excision for rectal cancer. Colorectal Dis 8(1):15-22

3. Welsh FK, McFall M, Mitchell G, Miles WF, Woods WG (2003) Pre-operative short-course radiotherapy is associated with faecal incontinence after anterior resection. Colorectal Dis 5(6):563-568
4. Pollack J, Holm T, Cedermark B, Holmstrom B, Mellgren A (2006) Long-term effect of preoperative radiation therapy on anorectal function. Dis Colon Rectum 49(3):345-352

5. Heriot AG, Tekkis PP, Constantinides V, Paraskevas P, Nicholls RJ, Darzi A et al (2006) Meta-analysis of colonic reservoirs versus straight coloanal anastomosis after anterior resection. Br J Surg 93(1):19-32

6. Sailer M, Fuchs KH, Fein M, Thiede A (2002) Randomized clinical trial comparing quality of life after straight and pouch coloanal reconstruction. Br J Surg 89(9):1108-1117

7. Miller AS, Lewis WG, Williamson ME, Holdsworth PJ, Johnston D, Finan PJ (1995) Factors that influence functional outcome after coloanal anastomosis for carcinoma of the rectum. Br J Surg 82 (10):1327-1330

8. Molloy RG, Moran KT, Coulter J, Waldron R, Kirwan WO (1992) Mechanism of sphincter impairment following low anterior resection. Dis Colon Rectum 35(5):462-464

9. Lewis WG, Holdsworth PJ, Stephenson BM, Finan PJ, Johnston D (1992) Role of the rectum in the physiological and clinical results of coloanal and colorectal anastomosis after anterior resection for rectal carcinoma. Br J Surg 79(10):1082-1086

10. Otto IC, Ito K, Ye C, Hibi K, Kasai Y, Akiyama S et al (1996) Causes of rectal incontinence after sphincter-preserving operations for rectal cancer. Dis Colon Rectum 39(12):1423-1427

11. Matzel KE, Stadelmaier U, Muehldorfer S, Hohenberger W (1997) Continence after colorectal reconstruction following resection: impact of level of anastomosis. Int J Colorectal Dis 12(2):82-87

12. Gosselink MP, West RL, Kuipers EJ, Hansen BE, Schouten WR (1995) Integrity of the anal sphincters after pouch-anal anastomosis: evaluation with three-dimensional endoanal ultrasonography. Dis Colon Rectum 48(9):1728-1735

13. Gosselink MJ, Hop WC, Schouten WC (2001) Rectal compliance in females with obstructed defecation. Dis Colon Rectum 44 (7):971-977

14. Rockwood TH, Church JM, Fleshman JW, Kane RL, Mavrantonis C, Thorson AG et al (1999) Patient and surgeon ranking of the severity of symptoms associated with fecal incontinence: the fecal incontinence severity index. Dis Colon Rectum 42(12):1525-1532

15. Machado M, Nygren J, Goldman S, Ljungqvist O (2003) Similar outcome after colonic pouch and side-to-end anastomosis in low anterior resection for rectal cancer: a prospective randomized trial. Ann Surg 238(2):214-220

16. Lazorthes F, Chiotasso P, Gamagami RA, Istvan G, Chevreau P (1997) Late clinical outcome in a randomized prospective comparison of colonic $\mathrm{J}$ pouch and straight coloanal anastomosis. Br J Surg 84(10):1449-1451

17. Dehni N, Tiret E, Singland JD, Cunningham C, Schlegel RD, Guiguet $\mathrm{M}$ et al (1998) Long-term functional outcome after low anterior resection: comparison of low colorectal anastomosis and colonic J-pouch-anal anastomosis. Dis Colon Rectum 41(7):817-822 (discussion 822-823)

18. Seow-Choen F, Goh HS (1995) Prospective randomized trial comparing $\mathrm{J}$ colonic pouch-anal anastomosis and straight coloanal reconstruction. Br J Surg 82(5):608-610

19. Cavanaugh M, Hyman N, Osler T (2002) Fecal incontinence severity index after fistulotomy: a predictor of quality of life. Dis Colon Rectum 45:349-353

20. O'Riordain MG, Molloy RG, Gillen P, Horgan A, Kirwan WO (1992) Rectoanal inhibitory reflex following low stapled anterior resection of the rectum. Dis Colon Rectum 35(9):874-878

21. Vassilakis JS, Pechlivanides G, Zoras OJ, Vrachasotakis N, Chrysos E, Tzovaras G et al (1995) Anorectal function after low anterior resection of the rectum. Int J Colorectal Dis 10(2):101-106

22. Hallbook O, Nystrom PO, Sjodahl R (1997) Physiologic characteristics of straight and colonic J-pouch anastomoses after rectal excision for cancer. Dis Colon Rectum 40(3):332-338 
23. Rasmussen OO, Petersen IK, Christiansen J (2003) Anorectal function following low anterior resection. Colorectal Dis 5 (3):258-261

24. Gervaz P, Rotholtz N, Pisano M, Kaplan E, Secic M, Coucke P et al (2001) Quantitative short-term study of anal sphincter function after chemoradiation for rectal cancer. Arch Surg 136(2):192-196

25. Kusunoki M, Shoji Y, Yanagi H, Kamikonya N, Sakanoue Y, Hishikawa $Y$ et al (1993) Anorectal function after preoperative intraluminal brachytherapy and colonic $\mathrm{J}$ pouch-anal anastomosis for rectal carcinoma. Br J Surg 80(7):933-935

26. Amin AI, Hallbook O, Lee AJ, Sexton R, Moran BJ, Heald RJ (2003) A 5-cm colonic $\mathrm{J}$ pouch colo-anal reconstruction following anterior resection for low rectal cancer results in acceptable evacuation and continence in the long term. Colorectal Dis 5(1):33-37

27. Dehni N, McNamara DA, Schlegel RD, Guiguet M, Tiret E, Parc R (2002) Clinical effects of preoperative radiation therapy on anorectal function after proctectomy and colonic J-pouch-anal anastomosis. Dis Colon Rectum 45(12):1635-1640

28. Zimmerman DD, Gosselink MP, Hop WC, Darby M, Briel JW, Schouten WR (2003) Impact of two different types of anal retractor on fecal continence after fistula repair: a prospective, randomized, clinical trial. Dis Colon Rectum 46(12):1674-1679

29. Seow-Choen A, Tsunoda A, Nicholls RJ (1991) Prospective randomized trial comparing anal function after handsewn ileoanal anastomosis versus stapled ileoanal anastomosis without mucosectomy in restorative proctocolectomy. Br J Surg 78(4):430-434

30. Luukkonen P, Jarvinen H (1993) Stapled versus hand sutured ileoanal anastomosis in restorative proctocolectomy: a prospective randomized trial. Arch Surg 128(4):437-440

31. Reilly WT, Pemberton JH, Wolff BG et al (1997) Randomized prospective trial comparing ileal pouch-anal anastomosis performed by excising the anal mucosa to ileal pouch-anal anastomosis. Ann Surg 225(6):666-676

32. Lin JK, Wang HS, Yang SH, Jiang JK, Chen WS, Lin TC (2002) Comparison between straight and J-pouch coloanal anastomoses in surgery for rectal cancer. Surg Today 32(6):487-492

33. rHida J, Yoshifuji T, Tokoro T, Inoue K, Matsuzaki T, Okuno K et al (2004) Comparison of long-term functional results of colonic Jpouch and straight anastomosis after low anterior resection for rectal cancer: a five-year follow-up. Dis Colon Rectum 47 (10): $1578-1585$

34. Araki $\mathrm{Y}$, Isomoto $\mathrm{H}$, Tsuzi $\mathrm{Y}$, Matsumoto $\mathrm{A}$, Yasunaga $\mathrm{M}$, Yamauchi K et al (1999) Functional results of colonic J-pouch anastomosis for rectal cancer. Surg Today 29(7):597-600

35. Ho YH, Tan M, Seow-Choen F (1996) Prospective randomized controlled study of clinical function and anorectal physiology after low anterior resection: comparison of straight and colonic $\mathrm{J}$ pouch anastomoses. Br J Surg 83(7):978-980

36. Ho YH, Brown S, Heah SM, Tsang C, Seow-Choen F, Eu KW et al (2002) Comparison of J-pouch and coloplasty pouch for low rectal cancers: a randomized, controlled trial investigating functional results and comparative anastomotic leak rates. Ann Surg 236(1):49-55
37. Furst A, Burghofer K, Hutzel L, Jauch KW (2002) Neorectal reservoir is not the functional principle of the colonic J-pouch: the volume of a short colonic J-pouch does not differ from a straight coloanal anastomosis. Dis Colon Rectum 45(5):660-667

38. Lazorthes F, Gamagami R, Chiotasso P, Istvan G, Muhammad S (1997) Prospective, randomized study comparing clinical results between small and large colonic J-pouch following coloanal anastomosis. Dis Colon Rectum 40(12):1409-1413

39. Hida J, Yasutomi M, Fujimoto K, Okuno K, Ieda S, Machidera N et al (1996) Functional outcome after low anterior resection with low anastomosis for rectal cancer using the colonic J-pouch. Prospective randomized study for determination of optimum pouch size. Dis Colon Rectum 39(9):986-991

40. Gosselink MP, Darby M, Zimmerman DD, Smits AA, van Kessel I, Hop WC et al (2005) Long-term follow-up of retrograde colonic irrigation for defaecation disturbances. Colorectal Dis 7(1):65-69

41. van Duijvendijk P, Slors JF, Taat CW, van Tets WF, van Tienhoven G, Obertop $\mathrm{H}$ et al (2002) Prospective evaluation of anorectal function after total mesorectal excision for rectal carcinoma with or without preoperative radiotherapy. Am J Gastroenterol 97(9):2282-2289

42. Montesani C, Pronio A, Santella S, Boschetto A, Aguzzi D, Pirozzi R, D'Amato A, Vestri A (2004) Rectal cancer surgery with sphincter preservation: functional results related to the level of anastomosis. Clinical and instrumental study. Hepatogastroenterology 51(57): 718-721

43. Matthiessen P, Hallbook O, Andersson M, Rutegard J, Sjodahl R (2004) Risk factors for anastomotic leakage after anterior resection of the rectum. Colorectal Dis 6(6):462-469

44. Eriksen MT, Wibe A, Norstein J, Haffner J, Wiig JN, Norwegian Rectal Cancer Group (2005) Anastomotic leakage following routine mesorectal excision for rectal cancer in a national cohort of patients. Colorectal Dis 7:51-57

45. Walker KG, Bell SW, Rickard MJ, Mehanna D, Dent OF, Chapuis PH, Bokey EL (2004) Anastomotic leakage is predictive of diminished survival after potentially curative resection for colorectal cancer. Ann Surg 240(2):255-259

46. Dehni N, Parc R, Church JM (2003) Colonic J-pouch-anal anastomosis for rectal cancer. Dis Colon Rectum 46(5):667-675

47. Alberts JC, Parvaiz A, Moran BJ (2003) Predicting risk and diminishing the consequences of anastomotic dehiscence following rectal resection. Colorectal Dis 5(5):478-482

48. Z'Graggen K, Maurer CA, Birrer S, Giachino D, Kern B, Buchler MW (2001) A new surgical concept for rectal replacement after low anterior resection: the transverse coloplasty pouch. Ann Surg 234(6):780-785 (discussion 785-787)

49. Mantyh CR, Hull TL, Fazio VW (2001) Coloplasty in low colorectal anastomosis: manometric and functional comparison with straight and colonic J-pouch anastomosis. Dis Colon Rectum 44(1):37-42

50. Remzi FH, Fazio VW, Gorgun E, Zutshi M, Church JM, Lavery IC et al (2005) Quality of life, functional outcome, and complications of coloplasty pouch after low anterior resection. Dis Colon Rectum 48(4):735-743 